\title{
AUTOMATISASI PENENTUAN JALUR KONEKSI INTERNET PADA TIGA PROVIDER
}

\author{
Galih Dwi Wicaksono, Haruno Sajati, Dwi Nugraheny \\ Program Studi Teknik Informatika, Sekolah Tinggi Teknologi Adisutjipto \\ galih.stta@gmail.com, iati r@yahoo.com, henynug@gmail.com
}

\begin{abstract}
Along with the times, the computer network has undergone many changes from time to time. Eventually, internet network is known. To test the reachability of a host on an IP address (internet protocol) network and to measure the round-trip time for messages sent from the host to the destination, computer needs to perform ping process. Ping operates by sending ICMP (Internet Control Message Protocol) echo request packets to the target host and waiting for an ICMP response. internet connection lane determination automation uses three providers done by comparing the smallest average value of the result of the ping. The test results are printed in the form of a statistical summary of the response packets received, including the minimum, maximum and average round-trip time. The signal strength is not directly proportional to the value of average, because the signal strength is affected by the report the data RSCP, throughput and quality of services covering CSSR (Call Setup Success Ratio), CCSR (Call Completion Success Ratio), DCR (Dropped Call Ratio) and BCR (Blocked Call Ratio) which can be used to optimize the network.
\end{abstract}

Keyword : internet, average, signal strength, network

\section{Pendahuluan}

Seiring dengan perkembangan zaman, jaringan komputer telah mengalami banyak perubahan dari masa ke masa. Hingga akhirnya, mulai dikenal jaringan internet. Internet merupakan singkatan dari Interconnection Networking. The network of the networks. Diartikan sebagai a global network of computer networks atau sebuah jaringan komputer dalam skala global/mendunia. Jaringan komputer ini berskala internasional yang dapat membuat masing-masing komputer saling berkomunikasi. Network ini membentuk jaringan inter-koneksi (Inter-connected network) yang terhubung melalui protokol TCP/IP.

Kecepatan akses internet dihitung dari jumlah data yang dikirim dalam satuan waktu. Jika mengirim $1 \mathrm{~kb}$ file/detik, berarti telah mengirim 1.000 byte, dengan 1 byte $=8$ bit maka data yang dikirim sama dengan 8.000 bit $=8 \mathrm{kbps}$ kilo bit per detik. Untuk satuan yang lebih besar mengggunakan Mbps mega bit per detik berarti 1000 kbps. Hingga akhirnya pada era globalisasi ini perkembangan teknologi semakin canggih dan hampir seluruhnya bekerja secara automatisasi. 


\section{Landasan Teori}

\subsection{Dial Up}

Jenis komunikasi antar komputer dengan menggunakan saluran telepon ataupun modem disebut dial up. Prosesnya yaitu komputer melalui modem melakukan pemanggilan telepon ke pelenggara jasa internet/provider, lalu jika sudah terhubung maka komputer akan segera mengakses internet dan kemudian mengakhiri koneksi dengan memutuskan hubungan telepon.

\subsection{APN (Access Point Name)}

Sebuah protokol komputer yang biasanya memungkinkan komputer pengguna untuk mengakses internet menggunakan jaringan telepon seluler adalah APN (Access Point Name). Untuk dapat mengakses internet maka harus melakukan pengaturan APN. Pengaturan tersebut harus sesuai dengan provider yang digunakan, karena setiap provider memiliki pengaturan yang berbeda.

\subsection{Modem GSM}

Modem yang menggunakan teknologi sistem telepon seluler (GPRS, HSPA, EVDO, dan lainlain) sebagai sistem transfer data adalah modem GSM. Provider GSM diantaranya yaitu telkomsel, $\mathrm{xl}$, indosat, axis, dan lain sebagainya. Sebagian besar modem GSM dilengkapi dengan slot memori microSD dan jack untuk antena eksternal tambahan. GSM adalah singkatan dari global system for mobile. Beberapa operator mengenakan tarif tetap per data yang ditransfer per kilobyte, megabyte, dan gigabyte.

\subsection{Command Promt (CMD)}

Program windows yang bertindak sebagai interpreter perintah DOS seperti garis. Baris perintah penerjemah pada OS/2, Windows CE dan Windows NT berbasis sistem operasi (termasuk Windows 2000, Windows XP, Windows Vista, Windows Server 2003 dan Windows Server 2008) disebut cmd.exe. Command Prompt adalah command-line interpreter yang disediakan Microsoft pada OS/2, Windows CE dan pada sistem operasi Windows NT-based (termasuk Windows, Windows 2000, Windows XP, Windows Vista, Windows 7, Windows Server 2003 dan Windows Server 2008).

\subsection{Ping}

Sebuah jaringan komputer utilitas perangkat lunak administrasi yang digunakan untuk menguji reachability dari host pada alamat IP (internet protocol) jaringan dan untuk mengukur waktu pulang-pergi untuk pesan yang dikirim dari host ke komputer tujuan. Ping merupakan singkatan dari packet internet groper. Ping beroperasi dengan mengirimkan ICMP (internet control message protocol) echo paket permintaan ke host target dan menunggu respon ICMP. Dalam proses itu mengukur waktu dari transmisi ke penerimaan (waktu pulang-pergi) dan mencatat setiap packet loss. Hasil tes dicetak dalam bentuk ringkasan statistik dari paket respon yang diterima, termasuk minimum, maksimum, rata-rata (average) waktu pulang-pergi paket data, dan kadang-kadang standar deviasi dari mean. Average untuk jaringan internet yang baik sekitar 250 atau maksimal 300 .

\subsection{COM Port}

Komponen yang berhubungan dengan input/output data serial serta bersifat physically, artinya akan ada tegangan sebagai representasi logika 1 dan 0 yang keluar masuk komputer secara serial 
atau berderet melalui port serial disebut juga com port. Sarana komunikasi data serial antara komputer dengan komputer lain, maupun dengan peralatan serial lainnya adalah fungsi dari com port.

\subsection{Magenta System}

Magenta System Internet Packet Pemantauan Komponen adalah seperangkat komponen delphi yang dirancang untuk menangkap dan memonitor paket internet baik menggunakan soket mentah atau driver perangkat WinPcap. Hardware memungkinkan, paket ethernet dapat ditangkap dan ditafsirkan, dan statistik dipelihara tentang lalu lintas. Penggunaan pemantauan paket termasuk sejumlah lalu lintas internet berdasarkan alamat IP dan layanan, pemantauan alamat IP eksternal atau internal dan layanan yang diakses, diagnostik jaringan, dan banyak aplikasi lainnya.

Komponen magenta system mencakup dua aplikasi demonstrasi, salah satu yang menampilkan paket baku, lain yang total lalu lintas internet. Komponen meliputi berbagai filter untuk mengurangi jumlah paket yang harus diproses, dengan memungkinkan alamat IP tertentu untuk diabaikan, LAN masker untuk mengabaikan lalu lintas lokal, dan mengabaikan non-IP lalu lintas seperti ARP. Mendeteksi jenis status koneksi, APN, nama provider, dan IP dalam sebuah sistem komputer adalah fungsi dari magenta system.

\subsection{Arsitektur Jaringan Internet}

Pembangunan arsitektur jaringan internet dapat menggunakan elemen jaringan yang masih memungkinkan. Elemen tersebut harus disesuaikan atau dimodifikasi sedemikian rupa supaya dapat berfungsi secara optimal pada jaringan. Selain itu penambahan elemen jaringan baru juga dibutuhkan untuk membangun paket data yang efektif. Rancangan arus komunikasi media elektronik yang berupa sebuah himpunan layer (lapisan) dan protokol, dimana layer bertujuan memberi layanan ke layer yang ada diatasnya.

\subsection{Kualitas Layanan (QoS)}

Kualitas layanan atau Quality of Service (QoS) meliputi CSSR, CCSR, DCR, dan BCR dihitung dari data parameter call events yaitu call setup, call attemp, call establish, drop call, dan block call. Call Setup adalah proses panggilan mulai dibangun oleh mobile station. Call Attemp adalah proses panggilan untuk meminta kanal pada node B. Call Established adalah proses panggilan sudah terjadi. Drop Call adalah proses panggilan berakhir secara tidak normal setelah kejadian Call Established. Block Call adalah proses panggilan berakhir secara tidak normal sebelum terjadi Call Established, misalnya disebabkan karena sibuknya kanal trafik. Quality of Service (QoS) merupakan mekanisme jaringan yang memungkinkan aplikasi-aplikasi atau layanan dapat beroperasi sesuai dengan yang diharapkan.

CSSR (Call Setup Success Ratio) merupakan prosentase tingkat keberhasilan panggilan oleh ketersediaan kanal suara yang sudah dialokasikan untuk mengetahui kesuksesan panggilan, maka ditandai dengan tone saat terkoneksi dengan ponsel lawan bicara. CCSR (Call Completion Success Ratio) adalah prosentase dari keberhasilan proses panggilan yang dihitung dari MS penelepon melakukan panggilan sampai dengan panggilan tersebut terjawab oleh penerima. DCR (Dropped Call Ratio) adalah prosentase banyaknya panggilan yang jatuh atau putus setelah kanal pembicaraan digunakan. BCR (Blocked Call Ratio) adalah prosentase kepadatan panggilan yang disebabkan karena keterbatasan kanal. 


\subsection{Throughput}

Konsep bandwidth tidak cukup untuk menjelaskan kecepatan jaringan dan apa yang terjadi di jaringan, untuk itulah konsep throughput muncul. Throughput adalah bandwidth aktual yang terukur pada suatu ukuran waktu tertentu dalam suatu hari menggunakan rute internet yang spesifik ketika sedang melakukan download suatu file.

\subsection{RSCP}

Perhitungan RSCP diperoleh dari perhitungan link budget sebagai perbandingan dengan data pengukuran drive test dengan satuan $\mathrm{dBm}$. Tahapan dalam perhitungan RSCP (Receive Signal Code Power) dilakukan dengan perhitungan prediksi pathloss, perhitungan EIRP dan perhitungan RSCP secara teori. EIRP (Efective Isotropic Radiated Power) adalah nilai daya yang dipancarkan antena directional untuk menghasilkan puncak daya yang diamati pada arah radiasi maksimum penguatan antena. Pathloss adalah rugi-rugi lintasan propagasi (dB) yang diperoleh dari persamaan.

\subsection{Pemrograman Delphi}

Sebuah perangkat lunak (bahasa pemrograman) untuk membuat program/ aplikasi komputer berbasis windows. Delphi merupakan bahasa pemrograman berbasis objek, artinya semua komponen yang ada merupakan objek-objek. Ciri sebuah objek adalah memiliki nama, property dan method/ procedure. Delphi disebut juga visual programming artinya komponen-komponen yang ada tidak hanya berupa teks tetapi muncul berupa gambar-gambar. Dalam interface program delphi dibagi dalam beberapa interface. Ide munculnya delphi berasal dari bahasa pemrograman pascal. Berbagai aplikasi dapat dibuat dengan delphi termasuk aplikasi untuk mengolah teks, grafik, angka database, dan aplikasi web. Delphi mempunyai lingkungan pemrograman terpadu Intregrated Development Environment (IDE) seperti menu, speed bar, component palette, form designer, code editor, object tree view dan object inspector.

\section{Analisa Dan Perancangan Sistem}

\subsection{Flowchart Sistem}

Flowchart Sistem pada Sistem Automatisasi Penentuan Jalur Koneksi Internet Pada Tiga Provider bisa dilihat pada gambar 1. 


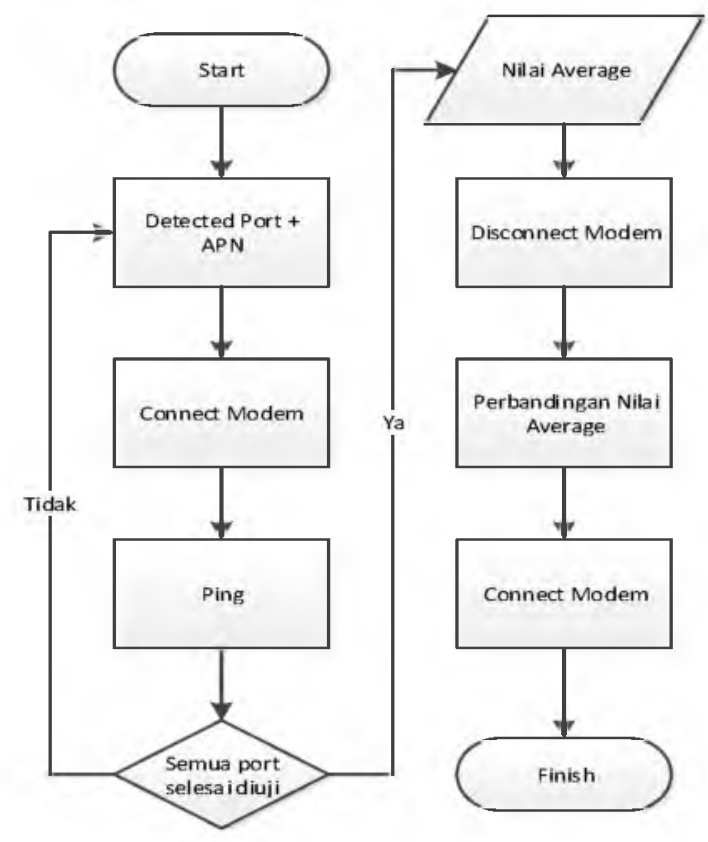

\section{Gambar 1 Flowchart Sistem Automatisasi Penentuan Jalur Koneksi Internet Pada Tiga Provider}

Pada gambar 1 flowchart sistem, langkah awal yang dilakukan yaitu menjalankan proses detected port dan APN yang aktif. Setelah mendapatkan port dan APN yang aktif lalu akan connect automatis kemudian melakukan proses ping, jika iya maka akan melakukan proses perulangan. Jika tidak maka lanjut membandingkan nilai average yang didapat dari hasil ping. Setelah diproses membandingkan nilai average, modem dengan nilai average terkecil akan langsung dilakukan proses connect melalui port dengan dial up.

\subsection{Diagram Konteks}

Diagram Konteks pada Sistem Automatisasi Penentuan Jalur Koneksi Internet Pada Tiga Provider bisa dilihat pada gambar 2 .

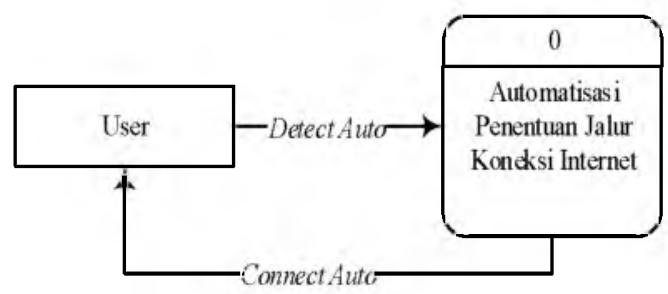

Gambar 2 Diagram Konteks Automatisasi Penentuan Jalur Koneksi Internet Menggunakan Tiga Provider

Pada gambar 2 hanya terdapat satu entitas yaitu user. User mengaktifkan button automatis pada sistem, lalu sistem akan melakukan proses yang telah ditanamkan, kemudian sistem akan memberikan output berupa hasil com modem, kekuatan sinyal, nilai average, jenis provider dan auto connect kepada $u$ ser. 


\subsection{Diagram Level 0}

Diagram Level 0 pada Sistem Automatisasi Penentuan Jalur Koneksi Internet Pada Tiga Provider bisa dilihat pada gambar 3 .

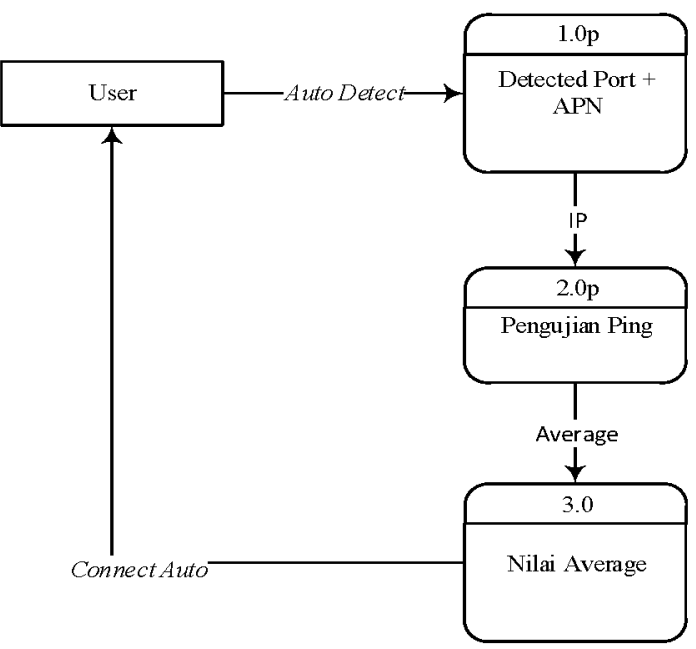

\section{Gambar 3 DFD Level 0 Sistem Automatisasi Penentuan Jalur Koneksi Internet Pada Tiga Provider}

Pada Gambar 3 menjelaskan bahwa, user melakukan auto detect, kemudian diproses detected sehingga didapat informasi tentang port dan APN yang aktif, jenis jaringan, kekuatan sinyal, dan IP. IP digunakan sebagai inputan untuk dilakukan proses ping ke google untuk mendapatkan nilai average. Setelah semua nilai average telah didapat kemudian dilakukan proses perbandingan ketiga nilai average, modem dengan nilai average yang terkecil maka modem itu yang akan connect. Kemudian hasil ping dari proses ping google akan dikembalikan ke user.

\subsection{Diagram Level 1}

Diagram Level 1 pada Sistem Automatisasi Penentuan Jalur Koneksi Internet Pada Tiga Provider bisa dilihat pada gambar 4.

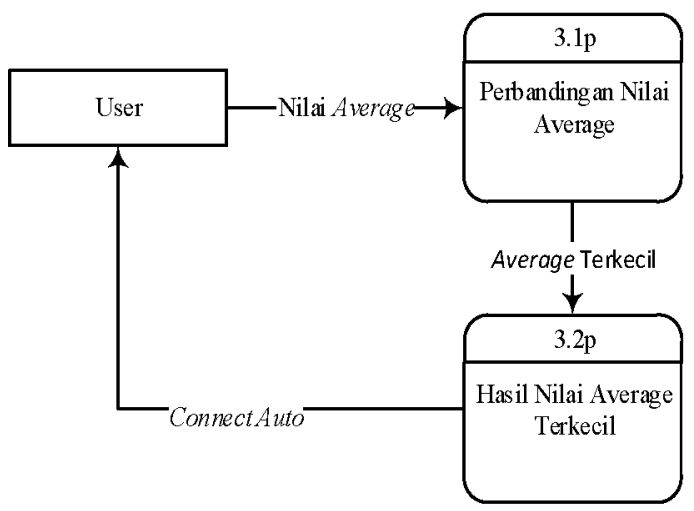

\section{Gambar 4 DFD Level 1 Sistem Automatisasi Penentuan Jalur Koneksi Internet Pada Tiga Provider}

Pada Gambar 4 menjelaskan bahwa, user memasukkan nilai average, kemudian melakukan proses perbandingan nilai average. Setelah semua nilai average telah didapat kemudian dilakukan proses perbandingan ketiga nilai average, modem dengan nilai average yang terkecil maka modem 
itu yang akan connect. Nilai average terkecil digunakan sebagai inputan untuk dilakukan proses hasil nilai average terkecil untuk dikembalikan ke user.

\subsection{Flowchart Program}

Flowchart Program pada Sistem Automatisasi Penentuan Jalur Koneksi Internet Pada Tiga Provider bisa dilihat pada gambar 5.

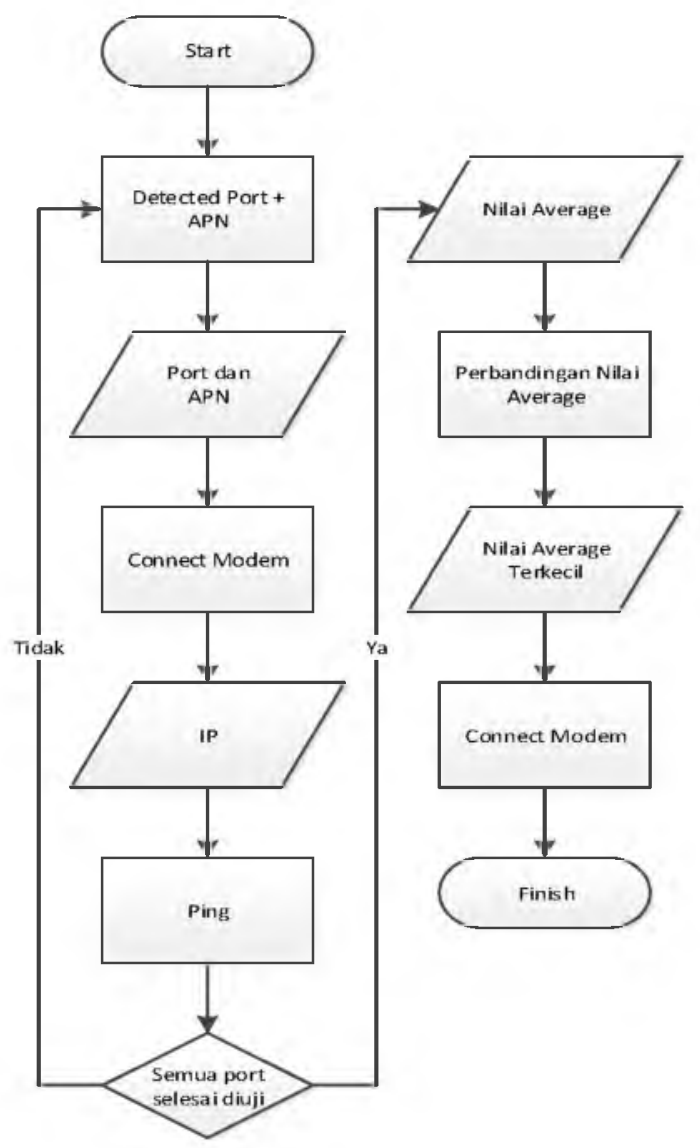

Gambar 5 Flowchart Program Automatisasi Penentuan Jalur Koneksi Internet Pada Tiga Provider

Pada Gambar 5 dari flowchart program, langkah awal yang dilakukan yaitu menjalankan proses detected port dan APN yang aktif. Setelah mendapatkan port dan APN yang aktif lalu akan connect automatis kemudian melakukan proses ping, jika iya maka akan melakukan proses perulangan sampai semua modem telah teridentifikasi. Jika tidak maka lanjut membandingkan nilai average yang didapat dari hasil ping. Setelah diproses membandingkan nilai average, modem dengan nilai average terkecil akan langsung dilakukan proses connect melalui port dengan dial up. 


\section{Implementasi}

Adapun pengujian proses perbandingan nilai average dengan tiga modem dapat dilihat pada gambar 6 .

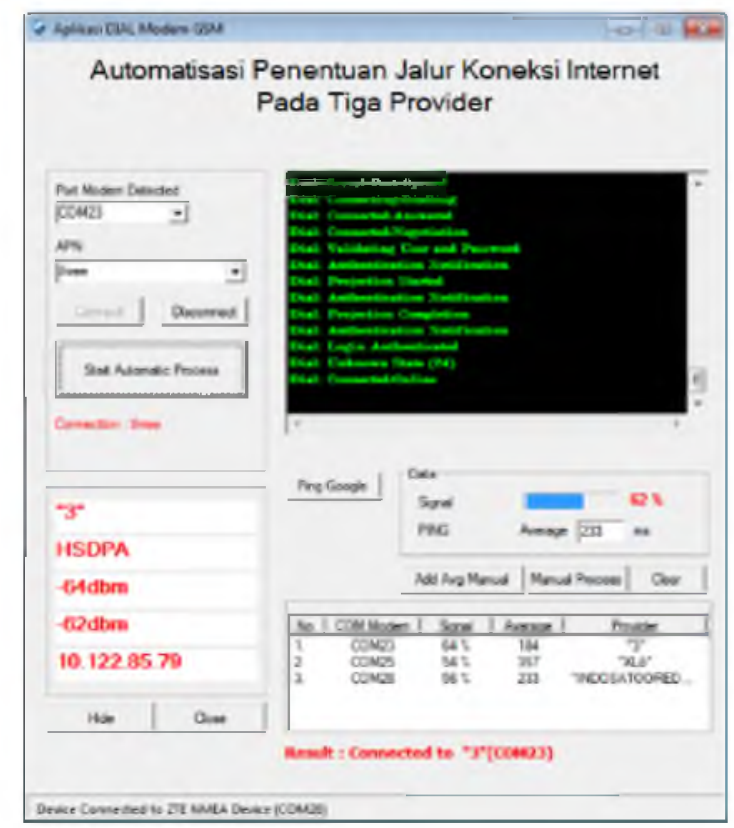

\section{Gambar 6 Perbandingan Nilai Average Pada Tiga Modem}

Pada gambar 6 pengujian perbandingan nilai average dengan tiga modem terdapat tiga data yang akan dilakukan proses perbandingan. Data yang nantinya akan diproses yaitu hanya nilai average. Perbandingan dilakukan dengan membandingkan ketiga data dengan mencari nilai average yang terkecil. Modem dengan nilai average terkecil maka modem tersebut yang dijadikan jalur koneksi internet terbaik. Proses connect dilakukan dengan menggunakan com port modem dan APN melalui dial up.

Kekuatan sinyal tidak berbanding lurus dengan nilai average, karena kekuatan sinyal dipengaruhi oleh report data RSCP, throughput dan kualitas layanan meliputi CSSR (Call Setup Success Ratio), CCSR (Call Completion Success Ratio), DCR (Dropped Call Ratio), dan BCR (Blocked Call Ratio) yang dapat digunakan untuk melakukan optimasi terhadap jaringan.

\section{Kesimpulan}

Setelah melaksanakan perancangan dan pengujian aplikasi Automatisasi Penentuan Jalur Koneksi Internet Pada Tiga Provider terdapat beberapa kesimpulan yang penulis buat diantaranya sebagai berikut :

a. Pengujian Detected Port dan APN berhasil dilakukan dan hasilnya sangat akurat, bisa dibuktikan dengan melihat pada device manager dan network connections.

b. Pengujian Ping membuktikan bahwa proses ping berhasil dilakukan dan hasilnya sangat akurat, bisa dilihat dari kesamaan alamat IP (internet protocol), jumlah data yang dikirimkan, dan TTL (time to live) waktu maksimum dari komputer saat mereply/membalas paket ICMP atau disebut juga latency/delay.

c. Pengujian dengan satu kali proses perbandingan nilai average pada dua modem, terdapat dua data yang akan diproses dengan membandingkan nilai average terkecil dan dalam 
pengujian dengan satu kali proses perbandingan nilai average pada tiga modem, terdapat tiga data yang akan diproses dengan membandingkan nilai average terkecil.

d. Pengujian proses perbandingan nilai average dengan dua modem yang berulang setiap 900 detik sampai jangka waktu total 2 jam 15 menit, nilai average terkecil dari kedua modem selalu berubah-ubah tergantung baik buruknya jaringan koneksi internet provider dan begitu juga dalam pengujian proses perbandingan nilai average dengan tiga modem.

Pengujian perbandingan kekuatan sinyal dengan nilai average membuktikan bahwa kekuatan sinyal tidak berbanding lurus dengan nilai average, karena kekuatan sinyal dipengaruhi oleh report data RSCP, throughput dan kualitas layanan meliputi CSSR (Call Setup Success Ratio), CCSR (Call Completion Success Ratio), DCR (Dropped Call Ratio), dan BCR (Blocked Call Ratio) yang dapat digunakan untuk melakukan optimasi terhadap jaringan.

\section{Daftar Pustaka}

[1] Delhendro, 2015. Pengertian dan Fungsi Modem GSM. http://www.delhendro.com/2015/04/pengertian-dan-fungsi-modem-gsm.html diakses tanggal 12 Oktober 2015 pukul 19.23 wib.

[2] Eka, Candra, Agung, 2014. Pengertian dan Perintah-perintah pada CMD / Command Prompt. http://agungekacandra.blogspot.co.id/2014/09/pengertian-dan-perintah-perintah-pada.html diakses tanggal 15 Oktober 2015 pukul 14.03 wib.

[3] Forouzan, Behrouz, 2007. Data Communications and Networking. McGraw-Hill Companies, Inc, New York.

[4] Graba, Jan, 2007. An Introduction to Network Programming with Java. Fourth Edition, British Library Cataloguing in Publication Data, United States of America.

[5] Harold, Elliotte Rusty, 2014. Java Network Programming. Developing Networked Applications, United States of America.

[6] Mubashir, Arif, 2012. Access Point Name (APN). http://arifmubashir.blogspot.co.id/2012/03/access-point-name-apn.html diakses tanggal 4 Februari 2016 pukul 21.42 wib.

[7] Mutiara, Rezi, 2010. Arsitektur Jaringan (Network Architecture). http://rezimutiarafenorita.blogspot.co.id/2011/07/arsitektur-iaringan.html diakses tanggal 12 Agustus 2015 pukul 10.32 wib.

[8] Pratama, Felix, 2010. Definisi Dial Up. https://www.academia.edu/7843924/Pengertian Dial Up Dial Up adalah Dial Up vaitu D ial Up merupakan arti Dial Up Definisi Dial Up diakses tanggal 26 Oktober 2015 pukul 14.53 wib.

[9] Rahmanto, Yuri, 2015. Pelatihan Pemrograman Delphi. http://www.jakapramana.com/2015/03/download-ebook-tutorial-belajar-borland.html di download tanggal 15 Oktober 2015 pukul 8.43 wib. 
[10] Romdhoni, Imam, 2010. Cara Kerja GPRS.

https://dhonconstantine.wordpress.com/2010/04/12/cara-keria-gprs/ diakses tanggal 20 Agustus 2015 pukul 17.04 wib.

[11] Setiaji, 2016. Cara Instal component COMPORT pada Delphi 7. http://masgideons.blogspot.co.id/2012/06/cara-instal-component-comport-pada.html diakses tanggal 27 Oktober 2015 pukul 15.34 wib.

[12] Sutanta, Edhy, 2005. Komunikasi Data dan Jaringan Komputer. Graha Ilmu, Cetakan Pertama.

[13] Syaikhuddin, Asrul, Wijayanti, Ari, Siswandari, N.A., 2012. Analisa Unjuk Kerja Layanan 3G di Surabaya. Departemen Teknik Elektro Surabaya.

[14] Systems, Magenta, 2016. Delphi Developers Internet Packet Monitoring Components. Croydon CR0 6ED, United Kingdom http://www.magsys.co.uk/delphi/magmonsock.asp diakses tanggal 5 November 2015 pukul 10.57 wib.

[15] Yulianto, 2013. Pengertian dari Throughput. https://vuliantol4.wordpress.com/2013/01/29/3pengertian-dari-throughput/ diakses tanggal 3 November 2015 pukul 15.35 wib. 